\title{
Fundamental Study on the Effect of High-frequency Vibration in the Vertical and Lateral Directions on Ride Comfort
}

\author{
Chizuru NAKAGAWA, Ph.D. \\ Senior Researcher, \\ Ergonomics Laboratory, Human Science Division \\ Ryohei SHIMAMUNE, Ph.D. \\ Manager, \\ R\&D Center of JR East Group, East Japan Railway Company \\ Ken WATANABE, Ph.D. \\ Senior Researcher,

\section{Erimitsu SUZUKI} \\ Senior Researcher, \\ Electromagnetic Applications Laboratory, Maglev Systems Technology Division \\ To develop a more suitable method of evaluating the ride comfort of railway vehicles, \\ including high-speed trains, a fundamental study was conducted on passenger sensitivity \\ to various frequencies of vibration with respect to ride comfort. Experiments were per- \\ formed on 54 subjects using an electrodynamic vibration system that can generate vibra- \\ tions in the frequency range of 1 to $80 \mathrm{~Hz}$ in the vertical and lateral directions. The results \\ of the experiments indicated that the subjects tended to experience greater discomfort when \\ exposed to high-frequency vibrations than presumed by Japan's conventional Ride Com-
} fort Level assessment method.

Keywords: ride comfort, ergonomics, high-speed trains, evaluation method

\section{Introduction}

A recent topic of discussion in regard to high-speed trains has been the increased magnitude of the components of high-frequency vibrations at around $30 \mathrm{~Hz}$, which influence passenger ride comfort [1]. Japan's conventional Ride Comfort Level (RCL) [2] assessment method is now increasingly seen as insufficient because it involves frequency-dependent weighting factors that are extremely small for such high frequencies.

To develop a more suitable method of evaluating the ride comfort of railway vehicles, including high-speed trains, a fundamental study was conducted on passenger sensitivity to various frequencies of vibration with respect to ride comfort.

\section{Ride Comfort Level (RCL)}

RCL is a method that evaluates ride comfort by calculating values using a Frequency Weighting Curve (FWC) based on Equivalent Sensitivity Contours (ESC) (Fig. 1). The ESC approach was modified by the former Japanese National Railways (JNR) on the basis of ISO 2631 (proposed in 1974, revised in 1985) [3]. The important point of focus is that ESC does not express changes in comfort/discomfort. The ESC value at each frequency corresponds to the same magnitude of vibration perceived by subjects as that of $20 \mathrm{~Hz}$, which is the reference frequency used for comparison $[4,5]$.
Figure 2 (a) shows the FWC based on ESC, Wk (ISO 2631-1 (proposed in 1997) [6]) and Wb (ISO 2631-4 (proposed in 2000) [7]) for the vertical direction, and Figure 2 (b) shows the FWC based on ESC and Wd (ISO 2631-1 (proposed in 1997) [6]) for the lateral direction. ISO 26311 is a revised edition of ISO 2631 (proposed in 1974), and presents the guidelines for general requirements. ISO 2631-4 presents the guidelines for evaluation of the effects of vibration and rotational motion on passenger and crew comfort in fixed-guideway transport systems.

The relationship between the ESC and FWC used in the RCL method is shown by the equation below.

Value of $F W C=-20 \log _{10}\left(A / A_{0}\right)(\mathrm{dB})$

$A$ : value of $E S C$

$A_{0}: 0.315$

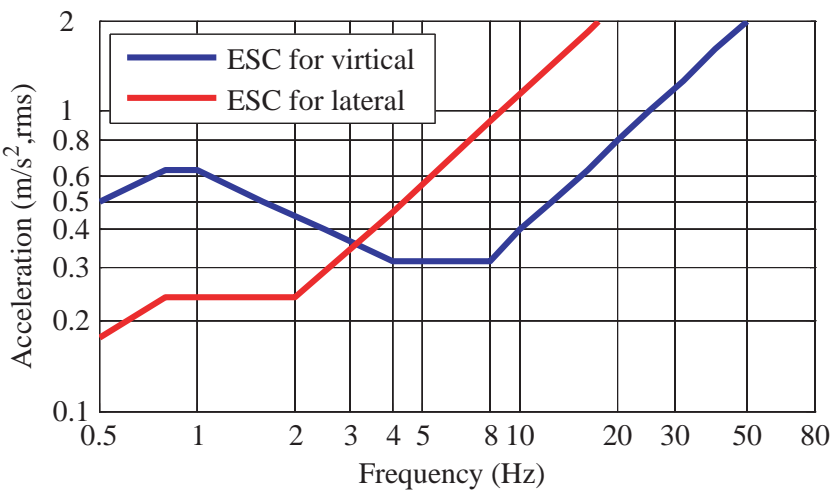

Fig. 1 Equivalent sensitivity contours (ESC) 


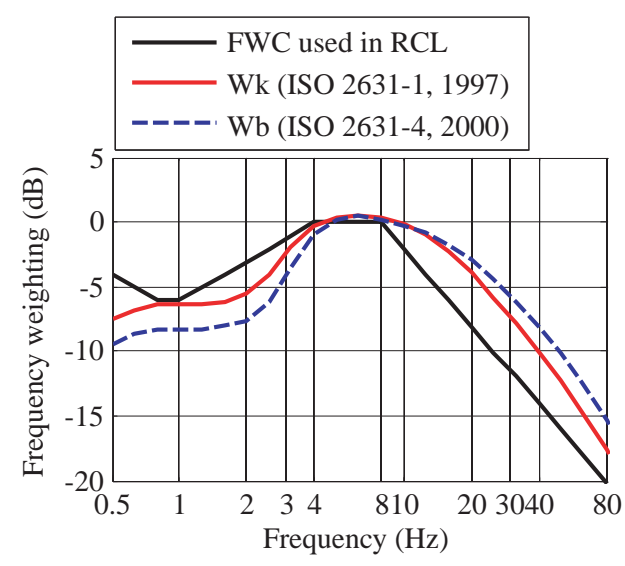

(a) Vertical direction

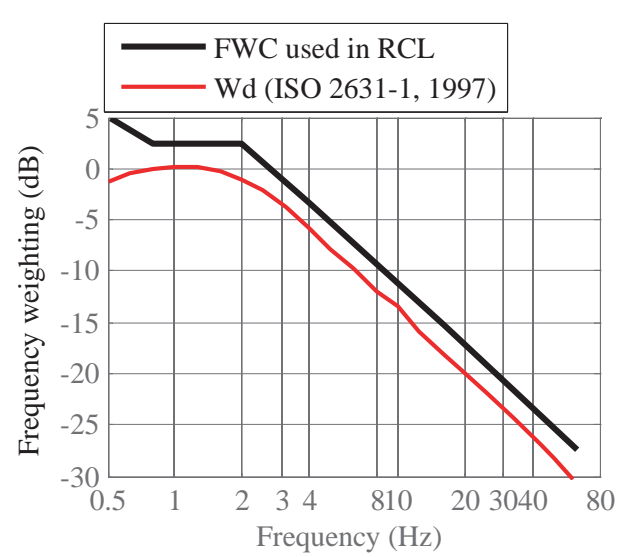

(b) Lateral direction

Fig. 2 Frequency weighting curves (FWC)

\section{Method of Experiments}

Two kinds of experiment were conducted on sensitivity of passengers to various frequencies of vibration with respect to ride comfort. The first (Test 1) used vertical sine waves as stimuli, and the second (Test 2) used lateral sine waves. The conditions of both experiments were identical except for the direction of vibration.

\subsection{Subjects}

The subjects of Test 1 (46 males and 9 females) all indicated that they were in good mental and physical health, and were all involved in the railway industry. Their ages ranged from 22 to 59 years with a mean of 38.9 , and their heights ranged from 154.5 to $184 \mathrm{~cm}$ with a mean of 169.4 .

The subjects of Test 2 (46 males and 8 females) also all indicated that they were in good mental and physical health, and again were all involved the railway industry. Their ages ranged from 22 to 59 years with a mean of 38.9 , and their heights ranged from 155 to $184 \mathrm{~cm}$ with a mean of 169

\subsection{Electrodynamic vibration system}

The experiments were performed using a three-axis simultaneous electrodynamic vibration system (produced by IMV Inc., Fig. 3) that generates vibrations in the frequency range of 1 to $80 \mathrm{~Hz}$.

\subsection{Procedure}

The subject sat on the left side of a double seat of the type used on Shinkansen high-speed express trains, which was installed on the platform of the vibration system. The platform vibration input used as a stimulus consisted of 16 types of vertical/lateral sine waves with frequencies of $1,2,4,5,6.3,8,10.1,12.7,16,20.2,25.4,32,40.3,51$, 64 and $81 \mathrm{~Hz}$, respectively. The magnitude of vibration acceleration was set such that the root-mean-squared (RMS) value was the same in each stimulus. The acceleration amplitude was increased gradually from $0.04 \mathrm{~m} /$ $\mathrm{s}^{2}$ to $1.7 \mathrm{~m} / \mathrm{s}^{2}$, then held at the maximum for two seconds

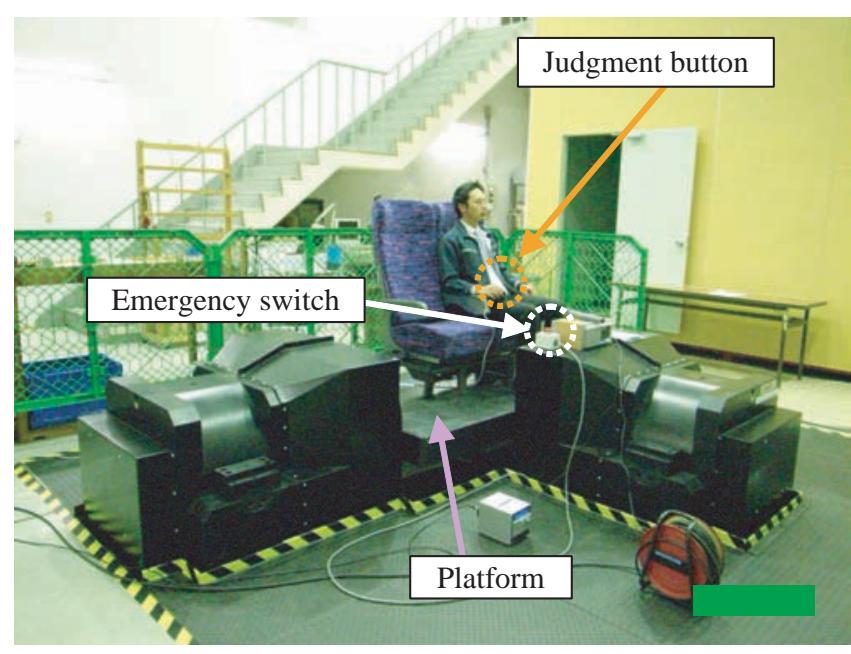

Fig. 3 Electrodynamic vibration system and a subject sitting on a double seat

before being decreased gradually and stopped (Fig. 4). The length of each stimulus was about one minute. The subjects pushed a button when they judged the magnitude of the vibration to be too large for them to permit from the perspective of ride comfort, on the assumption that they were riding a Shinkansen train.

The vibration of the platform was measured by an accelerometer in three directions: forward-backward (X),

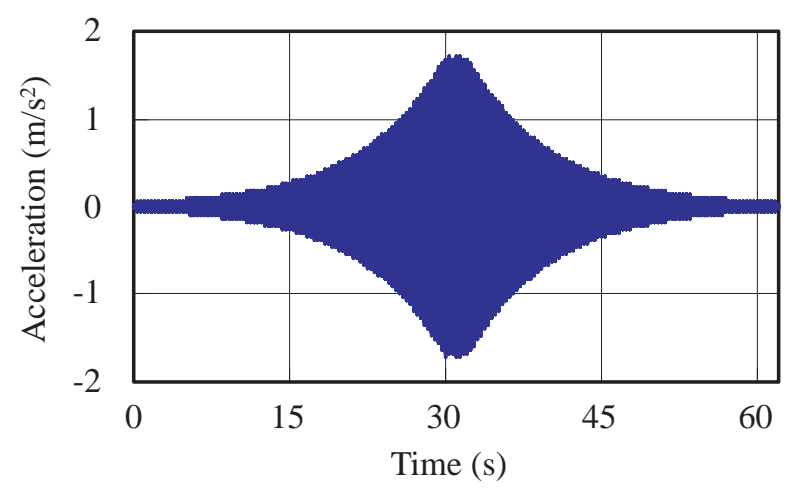

Fig. 4 Example of changes in vertical vibration as stimulus $(10.1 \mathrm{~Hz})$ 
lateral (Y), and vertical (Z).

The subjects answered a ride comfort questionnaire after each vibration test involving one of the 16 types of vertical/lateral sine waves with the respective frequencies outlined above. They scored the degree of discomfort in the questionnaire.

\section{Results of experiments}

The solid red line including the data points in Fig. 5 shows the average values of the vertical/lateral acceleration RMS on the platform when the subjects pushed the judgment button, and can also be described as the threshold vibration curve (TVC) for the Shinkansen. The solid gray line indicates the ESC in the RCL method. The figure on the left shows the results obtained using the vertical vibration stimuli; the minimum values of both curves are at around $5 \mathrm{~Hz}$, but the slope of the TVC is not as steep as that of the ESC above $10 \mathrm{~Hz}$. Similarly, in the figure on the right for lateral vibration, the minimum values of both curves are at around $2 \mathrm{~Hz}$, but the slope of
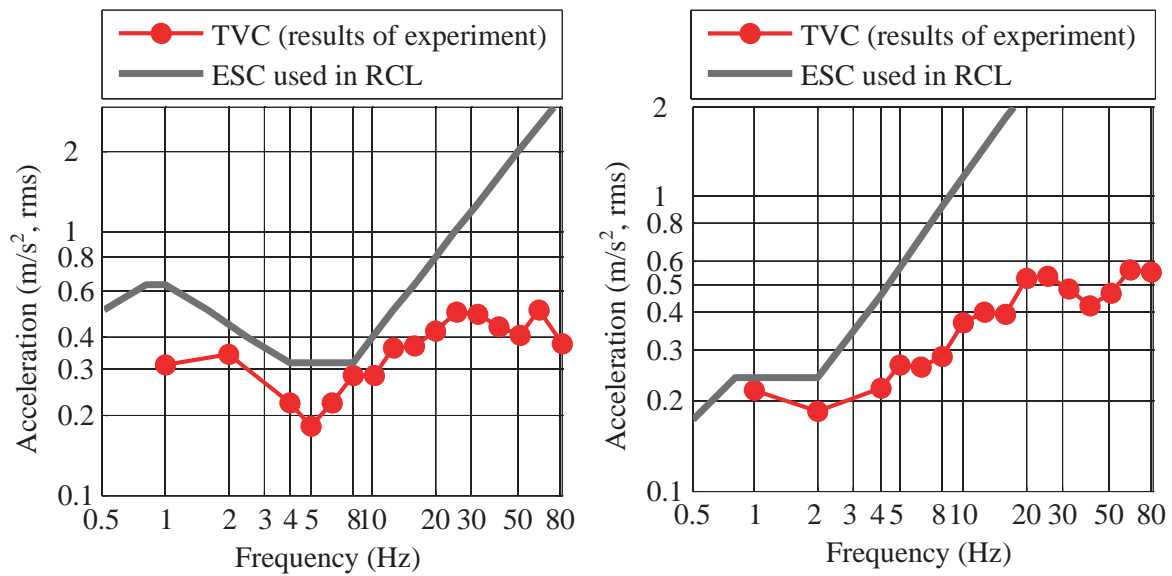

Fig. 5 Threshold vibration curve (TVC) and ESC used in RCL

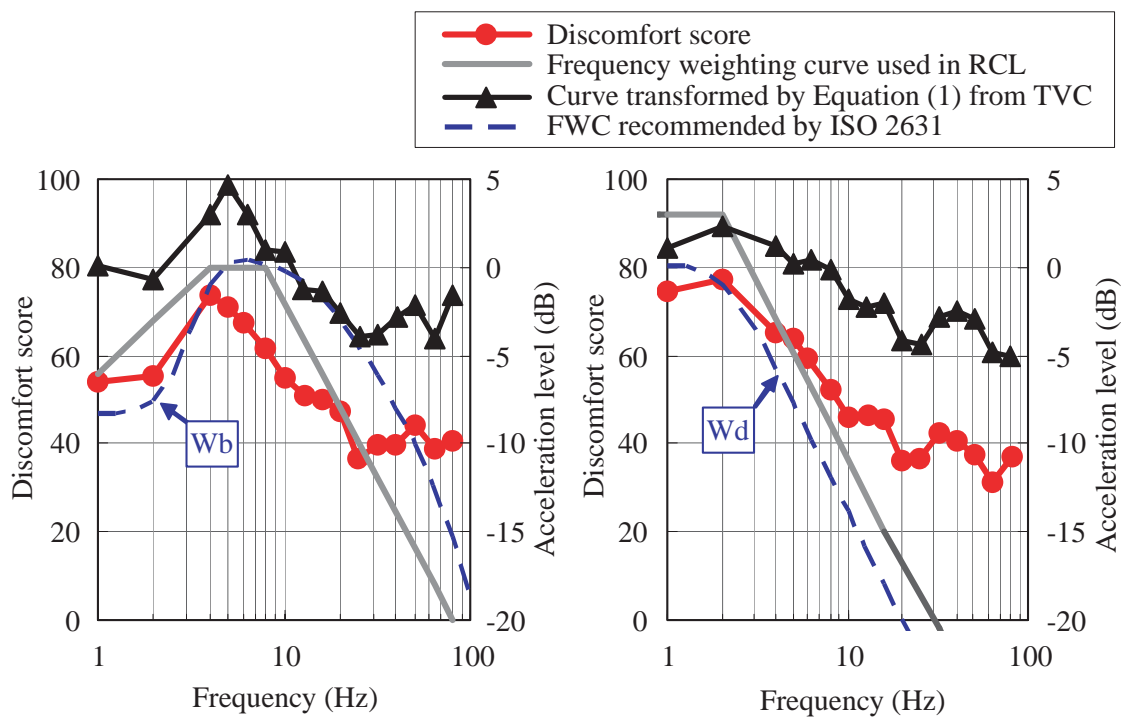

Fig. 6 Curve transformed by Equation (1) from TVC, frequency weighting curve (FWC) used in RCL and averages of the discomfort score in the questionnaire with respect to frequency 
in Chapter 2, the ESC value at each frequency corresponds to the same magnitude of vibration perceived by subjects as that of $20 \mathrm{~Hz}$, which is the reference frequency used for comparison. However, the criterion for ride comfort should not be magnitude but the level of comfort/discomfort. In the past, there would have been no problem using RCL because the high-frequency components of train vibrations were relatively small and the main frequency components that affected passenger ride comfort were at low frequencies, meaning that there was little difference between sensitivity to magnitude and comfort/discomfort in that range. However, the high-frequency components have recently increased to such a large degree that they now affect ride comfort. As a result, the problem of divergence of the ESC and TVC at high frequencies has become obvious.

\section{Conclusion}

This study investigated the influence of high-frequency vibration on ride comfort. The results of the experiments showed that the sensitivity of passenger ride comfort to high-frequency vertical/lateral vibration seems to be higher than that presumed by RCL. This outcome suggests that it is important to consider the influence of high-frequency vibration on ride comfort. However, it is not clear why the TVC does not increase at frequencies over $25 \mathrm{~Hz}$. It is presumed that audio sound of the same frequency as that of vibration is one factor that influences the rise in sensitivity.

In the next phase of this study, it will be necessary to research the influence of sound on ride comfort and verify the sensitivity of passengers with respect to ride comfort using actual train vibrations. This study is aimed at the development of a more suitable method of evaluating ride comfort of railway vehicles including Shinkansen trains.
This research is financially supported in part by the Japanese Government's Ministry of Land, Infrastructure, Transport and Tourism.

\section{References}

[1] Hirose, T., Takao, T. and Taguchi, H., "High frequency vibrations on high speed trains," Proc. the 3rd Transportation and Logistics Conference, Vol. 2, pp. 277-280, 1994 (in Japanese).

[2] Suzuki, H., "Research trends on riding comfort evaluation in Japan," Proceedings of the Institution of $\mathrm{Me}$ chanical Engineers, Vol. 212, Part F, pp.61-72, 1998.

[3] International Organization for Standardization, " $\mathrm{Me}$ chanical vibration and shock - Evaluation of human exposure to whole-body vibration - Part 1; General requirements," ISO 2631-1:1985, 1985.

[4] Miwa, T., "Evaluation method for vibration effect. Part 1. Measurements of threshold and equal sensation contours of whole body for vertical and horizontal vibrations," Industrial Health, Vol. 5, pp. 183-205, 1967.

[5] Miwa, T., "Evaluation method for vibration effect. Part 2. Measurements of equal sensation level for whole body between vertical and horizontal vibrations," Industrial Health, Vol. 5, pp.206-212 (1967).

[6] International Organization for Standardization, " $\mathrm{Me}$ chanical vibration and shock - Evaluation of human exposure to whole-body vibration - Part 1; General requirements," ISO 2631-1:1997, 1997.

[7] International Organization for Standardization, " $M e$ chanical vibration and shock - Evaluation of human exposure to whole-body vibration - Part 4; Guidelines for the evaluation of the effects of vibration and rotational motion on passenger and crew comfort in fixed-guideway transport systems," ISO 2631-4:2000, 2000. 